\title{
Significantly higher incidence of skin cancer than other malignancies in patients after heart transplantation. A retrospective cohort study in the Czech Republic
}

\author{
Zuzana Secnikova ${ }^{\mathrm{a}, \mathrm{b}}$, Dana Gopfertova ${ }^{\mathrm{b}}$, Lenka Hoskovac, Jana Hercogovaa ${ }^{\mathrm{a}}$, Martina Dzambova ${ }^{\mathrm{a}, \mathrm{b}}$, Anna Jirakovaa, \\ Lucie Rajska ${ }^{\mathrm{a}, \mathrm{b}}$, Filip Rob ${ }^{\mathrm{a}}$, Zdenek Smerhovsky ${ }^{\mathrm{b}}$
}

\begin{abstract}
Aims. To perform the first study in Czech Republic on heart transplant recipients (HTRs), compare the risks for different types of cancer and provide comprehensive analysis of skin cancer and other types of cancer morbidity from which we would be able to derive an evidence-based skin cancer surveillance program.

Materials and Methods. A retrospective cohort study was performed to determine and compare standardized morbidity ratio (SMR) of different types of cancer developed after heart transplantation. We analysed data obtained from medical documentation of 603 HTRs transplanted between 1993 and 2010.

Results. 191 incident cases of malignancy occurred in 123 HTRs (20.4\%). According to expectations, nonmelanoma skin cancer was the most frequent type of malignancy $(119$ cases) with SMR $7.6(P<0.001)$, followed by lung cancer with SMR 2.7 $(P<0.001)$. SMR for melanoma was $2.5, P=0.129$. Other types of cancer in HTRs (prostate and kidney cancer) were less frequent (SMR 2.06, $P=0.038$ and SMR 2.03, $P=0.122$ ).

Conclusion. The risk of malignancy development is significantly higher for HTRs compared to the general population. Squamous cell carcinoma of the skin is the most frequent type of cancer followed by basal cell carcinoma. These findings emphasise the importance of regular skin cancer screening in HTRs.
\end{abstract}

Key words: heart transplantation, skin cancer, immunosuppression

Received: October 31, 2014; Accepted with revision: February 26, 2015; Available online: March 26, 2015 http://dx.doi.org/10.5507/bp.2015.011

${ }^{a}$ Department of Dermatovenereology, $2^{\text {nd }}$ Faculty of Medicine, Charles University in Prague and Bulovka Hospital, Prague, Czech Republic

${ }^{b}$ Department of Epidemiology, $2^{\text {nd }}$ Faculty of Medicine, Charles University in Prague

'Department of Cardiology, Institute for Clinical and Experimental Medicine, Prague

Corresponding author:Zuzana Secnikova, e-mail:z.secnikova@gmail.com

\section{INTRODUCTION}

Organ transplant recipients are at increased risk of developing malignancies compared to the general population. The risk ranges from $4 \%$ to $18 \%$ and is estimated to be more than 100 times higher than the general population $^{1,2}$. According to current data, skin cancer is the most frequent malignancy among HTRs. A number of studies have also reported a higher incidence of other cancers, such as lymphoproliferative diseases, lung cancer or uterine and cervical dysplasia ${ }^{3,4}$. This study analyses the data of post-transplant malignancies among HTRs in the CzechRepublic. The incidence, spectrum, risk factors and clinical impact of post transplant malignancy were investigated retrospectively in a cohort of 603 heart transplant recipients.

\section{MATERIALS AND METHODS}

Patients who had undergone heart transplantation (HT) in the Transplant Centre at the Institute for Clinical and Experimental Medicine in Prague from 1993 - 2010 were included. Those with a history of cancer before HT and those who developed cancer within the first year after transplantation were excluded.The study was approved by the Ethics Committee of the Institute for Clinical and Experimental Medicine.

The majority of patients were men $(n=493 ; 81.8 \%)$, mean age 49.08 years ( \pm 11.61 years) at the time of HT. The mean age for women $(n=110,18.1 \%)$ was 48.15 ( \pm 13.19 years). Besides survivors, the study included 217 (35.8\%) deceased patients. HT was performed due to dilated cardiomyopathy, ischemic cardiac disease, valve disease, rheumatic fever and restrictive cardiomyopathy (Table 1). Three patients had to undergo heart re-transplantation, 18 patients after HT underwent further kidney transplantation and 2 patients underwent lung transplantation.

\section{Immunosuppressive regimen}

The standard initial post-transplant regimen of immunosuppressives consisted of steroids, calcineurine inhibitors (cyclosporine A or tacrolimus) and antimetabolites (mycophenolatemophetil or azathioprine). Since 2006, the perecentage treated with tacrolimus has gradually increased compared to cyclosporine. Mammalian target of rapamycine (mTOR) inhibitors (sirolimus, everolimus) have been used in the medication of HTRs since 2004/2005. 55 patients had mTOR inhibitors as part of 
Table 1. Distribution of heart transplant recipients according to cause of transplantation.

\begin{tabular}{lcc}
\hline Cause of HT & Absolute count & $\%$ \\
\hline Cardiomyopathy & 337 & $55.9 \%$ \\
Coronary arthery & 223 & $36.9 \%$ \\
disease & & \\
Valve disease & 22 & $3.6 \%$ \\
Retransplantation & 3 & $0.49 \%$ \\
Other & 18 & $2.9 \%$ \\
\hline
\end{tabular}

their immunosuppressive regimen in our cohort. Overall in 11 , treatment was initiated after the formation of skin cancer. The majority of HTRs in the cohort received a combination of immunosuppressive therapy which consisted of cyclosporine A, mycophenolatemophetil and corticosteroids (CS) (Table 2).

\section{Data processing and analysis}

Data were obtained from medical records and included gender, age at the time of HT, cause of HT, immunosuppressive regimen, rejection, type of cancer, age at the time of cancer diagnosis and cause of death.

Only cancer cases and carcinomas in situ with histopathological verification were included. The length of the follow up period was determined as the time from the date of the first transplantation to the last examination, cancer detection or death. If malignancy was detected, the date of diagnosis and type of cancer were recorded.

The results were compared with an external control group represented by the general Czech population using data from the National Registry for Oncologic Diseases. Age, sex and calendar year were used to define the adjusted estimate of standardized morbidity ratio (SMR) with $95 \%$ confidence intervals computed.

\section{RESULTS}

We investigated 686 patients who underwent transplantation in 1993-2010. A total of 83 patients were excluded from further analysis due to a diagnosis of cancer before HT or within the first year after HT, resulting in a final count of 603 patients (493 men and 110 women).
Table 2. Distribution of immunosuppressive regimen in heart transplant recipients.

\begin{tabular}{clc}
\hline $\begin{array}{c}\text { Most } \\
\text { frequent IS } \\
\text { regimens }\end{array}$ & \multicolumn{1}{c}{ Therapeutic combination } & $\mathrm{n}(\%)$ \\
\hline Group 1 & $\begin{array}{l}\text { Cyclosporine A } \\
\text { + mycophenolatemophetil + CS }\end{array}$ & 29.02 \\
Group 2 & $\begin{array}{l}\text { Tacrolimus } \\
\text { + mycophenolatemophetil + CS }\end{array}$ & 27.52 \\
Group 3 & Cyclosporine A + azathioprine + CS & 15.7 \\
\hline
\end{tabular}

191 incident cases of malignancy occurred in 123 patients (20.4\%). The median follow up was 6.4 years.

\section{Skin cancer}

Skin cancer was the most frequent type of malignancy (119 cases). The median time to develop non-melanoma skin malignancy was generally 10 years. Squamous cell carcinoma (SCC) represented the most frequent type of skin malignancy $(n=62,52.1 \%)$ followed by basal cell carcinoma (BCC) $(n=37,31.1 \%)$. Other types of skin cancer, localisation and median time to diagnosis are shown in Table 3. The most frequent localisation of skin tumours were in the head and neck (72.53\%). Multiple skin cancer developed in 29 patients, while 20 patients suffered from more than 3 tumours. An SMR for developing skin cancer was estimated to be $7.6(P<0.001 ; 95 \% \mathrm{CI}=5.94-9.59)$. Melanoma occurred in three patients, giving an SMR of $2.5(P=0.129)$ confirming no significantly increased incidence in comparison with the general population.

\section{Solid organ tumours and post-transplant lymphoproliferative disease (PTLD)}

Lung neoplasms $(n=22)$ were the most frequent type of cancer after non-melanoma skin cancer (NMSC). Adjusted relative risk for lung cancer was counted (SMR $=2.79,95 \%$ CI $1.80-4.15 ; P=0.1) .13$ patients in our cohort developed PTLD (12 men, 1 woman), including non-Hodgkin's lymphomas as well as Hodgkin's lymphoma and MGUS. The mean time to reach the diagnosis was 8 years, median survival time was 3 years. Other types of cancer detected in our study, median times to diagnosis and SMRs are shown in Table 4.

Table 3. Overview of skin cancer according to frequency, median time to diagnosis and localisation.

\begin{tabular}{|c|c|c|c|c|c|c|c|}
\hline & \multirow{2}{*}{$\begin{array}{c}\text { Absolute } \\
\text { count }\end{array}$} & \multirow{2}{*}{$\begin{array}{c}\text { Median time } \\
\text { to diagnosis } \\
\text { (years) }\end{array}$} & \multicolumn{5}{|c|}{ Localisation } \\
\hline & & & Head and neck & Upper limbs & Lower limbs & Trunk & Genitalia \\
\hline $\mathrm{BCC}$ & 37 & 12 & 21 & 3 & 2 & 9 & - \\
\hline $\mathrm{AK}$ & 11 & 12 & 8 & 2 & - & 1 & - \\
\hline m.Bowen & 4 & 6 & 2 & - & - & 2 & - \\
\hline $\mathrm{SCC}$ & 62 & 11 & 44 & 5 & 2 & 7 & 2 \\
\hline $\mathrm{MCC}$ & 1 & 5 & - & 1 & - & - & - \\
\hline $\mathrm{KA}$ & 2 & 12 & 2 & - & - & - & - \\
\hline Melanoma & 3 & 5 & 1 & - & - & 2 & - \\
\hline
\end{tabular}


Table 4. Overview of other types of cancer (except for NMSC) imaging absolute count, median time to diagnosis, median survival time and standardized morbidity ratios.

\begin{tabular}{lccccccc}
\hline Type of cancer & $\begin{array}{c}\text { Men } \\
(\%)\end{array}$ & $\begin{array}{c}\text { Women } \\
(\%)\end{array}$ & $\begin{array}{c}\text { Median time } \\
\text { to diagnosis } \\
\text { (years) }\end{array}$ & Alive & Deceased & $\begin{array}{c}\text { Median } \\
\text { survival } \\
\text { (years) }\end{array}$ & $\begin{array}{c}\text { SMR } \\
(95 \% \text { CI) }\end{array}$ \\
\hline Melanoma & $2(0.4)$ & $1(0.9)$ & 5 & 1 & 2 & 2 & 2.5 \\
Lung & $19(3.8)$ & $3(2.72)$ & 5.4 & 6 & 16 & 2 & $2.79(1.80-4.15)$ \\
Prostate & $10(2.02)$ & - & 5.5 & 7 & 3 & 2 & $2.03(1.05-3.62)$ \\
Kidney & $4(0.81)$ & $1(0.9)$ & 2.5 & 4 & 1 & 3 & $2.06(0.78-4.53)$ \\
Gastrointestinal & $14(2.8)$ & - & 6 & 6 & 8 & 3 & 0.122 \\
PTLD & $12(2.43)$ & $1(0.9)$ & 8 & 7 & 6 & 3 & - \\
\hline
\end{tabular}

\section{DISCUSSION}

Most of the available data show elevated risk of malignancy in organ transplant recipients ${ }^{5,6}$. In our study, we analysed the demographic characteristics, frequency and histopathological spectrum of tumours in 603 patients after HT. Our results confirmed that NMSC is the most frequent cancer in post-transplant period, followed by lung cancer and PTLD. In addition, a reversed SCC/BCC ratio (1.6:1) was observed in HTRs compared to the general population. Although it is thought that SCC in HTRs grows more aggressively, we recorded nopatient with metastases of SCC. However, recurrence of NMSC should be considered as a serious complication (29 of 70 NMSC patients, $41.4 \%$ ). Compared to other studies carried out recently, we noticed similar results in the case of risk for the development of NMSC. Jensen et al. reported an SIR of 5.6 for BCC and 113 for SCC ( ref. $^{7}$ ). In our study it was not possible to calculate adjusted risk for different types of NMSC, as data in the external group do not specify the exact type of NMSC.The relatively low incidence of skin cancer in a cohort of HTRs was recorded by Rinaldiet al. or Park et al. in a single centre in Korea ${ }^{8,9}$. Unlike most studies reported, the authors found significantly higher incidence of lung cancer (39\%) and non-Hodgkin lymphomas (20\%). However, the Korean authors found skin cancer in only $9 \%$ (ref. $^{9}$ ) of HTRs.

In contrast to the report by Lanza et al. from South Africa, where $33 \%$ of skin cancer developed were Kaposi's sarcomas ${ }^{10}$, we did not observe a single case. This phenomenon can be probably attributed to different epidemiologic conditions. Moreover, the prevalence of Kaposi's sarcoma after organ transplantation varies greatly according to the prevalence of HHV-8 infection in the population ${ }^{11}$. Early detection and adequate therapy is also recommended for keratoacanthoma ( 2 cases in our study). Keratoacanthoma may not be clearly distinguishable from SCC histologically and in organ transplant recipients should be considered as SCC (ref. ${ }^{12}$ ). The incidence of melanoma in transplant recipients remains a matter of discussion. Some authors deny any increase in the incidence compared to the general population ${ }^{13}$, whereas others reported up to 8-fold increase ${ }^{14}$. According to our results, we were not able to confirm a significantly higher incidence of melanoma in HTRs.

Similar to our study, Sobieszańska-Malek et al. also demonstrated a higher incidence of lung tumours in
HTRs, even exceeding the incidence of NMSC. The high incidence rate of pulmonary cancer in the analysed group was related to smoking before transplantation. In our cohort it was not possible to assess its association due to incomplete data. Similarly, higher incidence of PTLD has been observed in some recent studies ${ }^{5,6}$. There are still only a few data in the literature evaluating other types of malignancies in HTRs.

One of the primary goals of our study was to define surveillance intervals that would allow follow up of atrisk individuals. The purpose of this post-transplant surveillance is to manage preventive strategies focusing on NMSC, although further examination is presumably required. Several studies recommend stratifying patients according to the measure of risk for developing NMSC considering skin phototype, history of NMSC, family history and other relevant risk factors. Regular skin examination by a dermatologist is recommended once a year. In patients with in situ carcinoma (AK, Bowen's disease) a follow up in 6 month interval is advised. Due to lack of education among patients after HT in the Czech Republic we prefer regular examination by dermatologist every 6 months with the aim of early detection of skin cancer. In case of NMSC in history, even shorter intervals (3-6 months) appear to be advisable. We emphasize the need and importance of education on the benefits of UV protection, periodic self-skin examination and regular follow up. Furthermore, post-transplant management in HTRs requires an interdisciplinary collaboration with a view to early diagnosis of malignancies and their adequate treatment.

\section{CONCLUSION}

Conclusions drawn from our study should not be regarded as definitive and further detailed investigation of cancer complications in HTRs appears to be necessary.

\section{ABBREVIATIONS}

AK, Actinic keratosis; BCC, Basal cell carcinoma; HHV8, Human herpetic virus 8; HT, Heart transplantation; HTRs, Heart transplant recipients; KA, Keratoacanthoma; MB, Morbus Bowen; MCC, Merkell cell carcinoma; MGUS, Monoclonal gammopathy of un- 
determined significance; mTOR, Mammalian target of rapamycine; NMSC, Nonmelanoma skin cancer; PTLD, Post transplant lymphoproliferative disorders; SCC, Squamous cell carcinoma; SIR, Standardized incidence ratio; SMR, Standardized morbidity ratio

Acknowledgement: The study was supported by a grant of the Ministry of Health of the Czech Republic IGA MZČR NT 14203.

Author contributions: All authors contributed equally to preparing the manuscript.

Conflict of interest statement: None declared.

\section{REFERENCES}

1. Penn I. Incidence and treatment of neoplasia after transplantation J Heart Lung Transplant 1993;12(6):328-36.

2. Opelz G, Henderson R. Incidence of non-Hodgkin lymphoma in kidney and heart transplant recipients. Lancet 1993;342(88868887):1514-6.

3. Penn I. Why do immunosuppressed patients develop cancer? Crit Rev OncolHematol 1989;1(1):27-52.

4. Sobieszczańska-Małek M, Komuda K, Piotrowska M, Korewick J, Małek G, Leszek P, Zieliński T. Incidence of malignancies in cardiac allograft recipients - a single-center experience. Ann Transplant 2013;18:88-94.
5. Krynitz B, Edgren G, Lindelöf B, Baecklund E, Brattström C, Wilczek $\mathrm{H}$, Smedby KE. Risk of skin cancer and other malignancies in kidney, liver, heart and lung transplant recipients 1970 to 2008 - a Swedish population-based study. Int J Cancer 2013;132(6):1429-38.

6. Yagdi T,SharplesL,Tsui S, Large S,Parameshwar J. Malignancy after heart transplantation: analysis of 24-year experience at a single centre. J Card Surg 2009;24(5):572-9.

7. Jensen AO, Svaerke C, Farkas D, Pedersen L, Kragballe K, Sørensen HT. Skin cancer risk among solid organ recipients: a nationwide cohort study in Denmark. ActaDermVenereol 2010;90(5):474-9.

8. Rinaldi M, Pellegrini C, D'Armini AM, Aiello M, Negri M, Arbustini E, Ippoliti G, Viganò M. Neoplastic disease after heart transplantation: single center experience. Eur J CardiothoracSurg 2001;19(5):696-701.

9. Park GH, Chang SE, Won CH, Lee MW, Choi JH, Moon KC, Han DJ, Park SK, Kim JJ, Lee JW, Lee SG. Incidenceofprimaryskin cancerafter organ transplantation: An 18-year single-centerexperience in Korea. J Am AcadDermatol 2014;70(3):465-72.

10. Lanza RP, Cooper DK, Cassidy MJ, Barnard CN.Malignant neoplasms occurring after cardiac transplantation. JAMA 1983;249(13):1746-8.

11. Lebbé $C$, Legendre $C$, Francès $C$. Kaposi sarcoma in transplantation. Transplant Rev 2008;22(4):252-61.

12. Lapointe AK, Hofbauer G, Anliker M, Arnold A, Binet I, Hunger R, Kempf W, Pascual M, Pelloni F, Serra A, Laffitte E. Swiss clinical practice guidelines for skin cancer in organ transplant recipients. Rev Med Suisse 2010;6(246):854-9.

13. Lindelöf B, Sigurgeirsson B, Gäbel H, Stern RS. Incidence of skin cancer in 5356 patients following organ transplantation. Br J Dermatol 2000;143(3):513-9.

14. Le Mire L, Hollowood K, Gray D, Bordea C, Wojnarowska F. Melanomas in renal transplant recipients. Br J Dermatol 2006;154(3):472-7. 